\title{
ANÁLISE DA SUPLEMENTAÇÃO DE CARBOIDRATOS E SOLUÇÃO ISOTÔNICA SOBRE PARÂMETROS HEMATOLÓGICOS E BIOQUÍMICOS DE JOGADORES PROFISSIONAIS DE FUTEBOL EM CONDIÇÕES REAIS DE TREINAMENTO
}

\author{
DR. LUCIANO DE OLIVEIRA SIQUEIRA \\ Professor de bioquímica da Universidade de Passo Fundo \\ (Passo Fundo - Rio Grande do Sul - Brasil) \\ E-mail: luciano@upf.br \\ GRAD. JAÍSE BORTOLUZZI \\ Farmacêutica pela Universidade de Passo Fundo \\ (Passo Fundo - Rio Grande do Sul - Brasil) \\ E-mail: jaisebor@yahoo.com.br \\ GRAD. FABIO ZANIN \\ Farmacêutica pela Universidade de Passo Fundo \\ (Passo Fundo - Rio Grande do Sul - Brasil) \\ E-mail: fabio.a.zanin@ibest.com.br
}

Doutorado em bioquímica pela Universidade Federal do Rio Grande do Sul (ICBS/UFRGS),

\section{ESP. SUELLEN SAVI}

Especialização em hematologia e hemoterapia pela Universidade de Passo Fundo, Farmacêutica pela Universidade de Passo Fundo

(Passo Fundo - Rio Grande do Sul - Brasil)

E-mail: gatinha_su@yahoo.com.br

\section{GRAD. ANA PAULA DELIBERAL \\ Farmacêutica pela Universidade de Passo Fundo \\ (Passo Fundo - Rio Grande do Sul - Brasil) \\ E-mail: anadeliberal@yahoo.com.br}

GRAD. PATRÍCIA CASTELLI CANAL

Farmacêutica pela Universidade de Passo Fundo

(Passo Fundo - Rio Grande do Sul - Brasil)

E-mail: patricia_castellicanal@yahoo.com.br 


\section{DR. HUGO TOURINHO FILHO}

Doutorado em Educação Física pela Universidade de São Paulo (USP-SP),

Professor de Educação Física da Universidade de São Paulo

(Ribeirão Preto - São Paulo -Brasil)

E-mail: hugotourinho@hotmail.com

\section{DR. JOSÉ CLÁUDIO FONSECA MOREIRA}

Doutorado em Bioquímica pela Universidade Federal do Paraná,

Professor de Bioquímica na Universidade Federal do Rio Grande do Sul

(Porto Alegre - Rio Grande do Sul -Brasil)

E-mail:00006866@ufrgs.br

\section{RESUMO}

Avaliou-se o efeito de uma suplementação com carboidratos e bebidas esportivas sobre parâmetros laboratoriais em atletas de futebol de campo, em uma situação real de treinamento. Foram coletados $10 \mathrm{ml}$ de sangue venoso e $50 \mathrm{ml}$ de urina em repouso e 15 minutos após treinamento. Os resultados mostram que o exercício intenso causou um variável grau de estase urinária, bem como provocou alterações hidroeletrolíticas caracterizadas por uma diminuição na concentração sérica de sódio, potássio, magnésio, fósforo e glicose $(p<0,05)$, que não foi modificada por nenhum tipo de protocolo de suplementação nas condições propostas no presente estudo. A suplementação eletrolítica proposta mostrou-se limitada para evitar variações eletrolíticas e que a reposição deve ser avaliada à luz de um contexto ambiental e de treinamento.

PALAVRAS-CHAVE: Eletrólitos; equilíbrio hidroeletrolítico; estresse hídrico; suplemento dietético.

\section{INTRODUÇÃO}

Durante o exercício de predomínio aeróbio, a evaporação e o suor são os mecanismos mais importantes de termorregulação utilizado pelo corpo humano, transferindo calor continuamente para o meio ambiente à medida que a água é vaporizada pela pele. A sudorese é uma resposta fisiológica que se empenha em limitar o aumento da temperatura central através da secreção de água na pele para a evaporação, mas esta perda hídrica nem sempre é compensada pela ingestão de líquidos no processo de regulação da temperatura durante a realização do exercício físico. (CARVALHO et al., 20 I0; MACHADO-MOREIRA et al., 2006; PANZA et al., 2007).

É reconhecido o papel que o sistema renina-angiotensina (SRA) desempenha, não só na regulação da pressão arterial como também no controle hidroeletrolítico. A renina, que é secretada pelas células justaglomerulares do rim, cliva o angiotensinogênio produzido no fígado, gerando a angiotensina I, que dá origem à angiotensina 
II pela ação da enzima conversora de angiotensina (ECA). A angiotensina II age sobre o músculo liso vascular (funcional e estrutural) e sobre a regulação do volume hidroeletrolítico por meio da aldosterona. (IRIGOYEN et al., 200 I)

A desidratação faz com que a aldosterona diminua a excreção urinária de sódio aumentando sua reabsorção nos túbulos renais à custa de íons potássio e hidrogênio, elevando suas concentrações séricas, que se encontram diminuídas devido à prática esportiva. $O$ aumento da concentração sérica de sódio desencadeia o mecanismo da sede, levando o atleta a fazer uma reposição hídrica, muitas vezes realizada apenas com água, o que pode predispor o indivíduo ao desenvolvimento de distúrbios eletrolíticos. (MACHADO-MOREIRA et al., 2006; NAVES et al., 2003)

Um treinamento extenuante pode provocar um aumento na perda hídrica e eletrolítica não renal, o que pode acarretar num variável grau de desidratação e de desequilíbrio eletrolítico causando a redução do filtrado (ultrafiltrado do plasma realizado pelos rins, ainda passível de metabolização) e da urina. Estas alterações podem sobrecarregar a atividade renal pelo aumento da concentração de soluto e diminuição do volume hídrico, levando a formação de uma urina mais concentrada, densa, turva e rica em cilindros e muco, que podem facilmente ser analisados mediante a realização de um exame de urina. Além das alterações hemodinâmicas e metabólicas induzidas pela prática esportiva, pode-se observar a ocorrência de outras alterações como a hematúria (por trauma plantar exercido pelo impacto dos pés no solo, acidose metabólica e estresse oxidativo) e a proteinúria (provavelmente decorrente da grande pressão sobre a veia renal). (PERRELLA et al., 2005; TOPHAN, 2004, BELLINGHIERI et al., 2008, PONCE et al., I 988, LÜTHJE et al., 2004).

Uma rápida absorção de água e eletrólitos perdidos durante o exercício físico intenso pode retardar ou prevenir alterações na homeostase hidroeletrolítica, proporcionando melhor rendimento físico. A reposição de líquidos, eletrólitos e nutrientes promove a manutenção de volume de fluido extracelular e fornece energia ao músculo em exercício. (MONTEIRO et al., 2003; BORTOLOTTI, 20 I I; STEPHENS, 2007).

As bebidas isotônicas possuem concentrações de eletrólitos semelhantes ao sangue humano fazendo com que ocorra uma rápida absorção de líquido, uma vez que a biodisponibilidade de seus nutrientes foram largamente estudadas e padronizadas. São administradas após o aquecimento e durante a prática esportiva com o objetivo de elevar a glicemia para manter o organismo hidratado durante o treinamento/exercício. (MONTEIRO et al., 2003; CHEUVRONT, 20 I0).

Pouco se sabe sobre a influência desta suplementação/reposição sobre as proteínas e outros compostos nitrogenados do organismo, uma vez que alguns eletrólitos são importante cofatores de enzimas da rota glicolítica. Além disso, o 
surgimento de lesões musculares durante a prática esportiva, oriunda da proteólise muscular decorrente da demanda energética elevada, desequilíbrio da bomba de sódio e potássio eritrocitária, bem como a hemodiluição, poderia ser evitado pela adoção de protocolos definidos de suplementação. (BRITO et al., 2005; BORTOLOTTI, 20I I).

A utilização do chocolate ao leite e seus derivados (como manteiga de cacau, cacau em pó e chocolate amargo) tem sido foco de diversos estudos devido às suas propriedades antioxidantes e hipocolesterolêmico relacionados ao seu alto teor de flavonóides (epicatequina, catequina e procianidinas). (FRAGA et al., 2005; REIN et al., 2000; WAN et al., 200 I). Estudos prévios apresentados por Faller e Fialho (2009) ressaltam que, além do chocolate, outros alimentos amplamente disponíveis possuem estas e outras substâncias igualmente importantes para o organismo, como frutas e hortaliças.

Estudos experimentais mostraram que a suplementação regular de $100 \mathrm{~g}$ de chocolate ao leite por dia, o que corresponde a I I\% da dieta diária de um atleta, tem um potencial anti-aterogênico e é provável que induzem uma diminuição significativa na lipoperoxidação (TBARS), ácido úrico, lactato desidrogenase (LDH), status antioxidante (TRAP), pressão diastólica, níveis de colesterol total (fração LDL). (FRAGA et al., 2005). Além de flavonóides, chocolate também é rico em eletrólitos como cálcio e magnésio, justificando o seu uso na prevenção de distúrbios eletrolíticos induzida pelo desporto. No entanto, os estudos acima citados mostram seus benefícios somente quando usado cronicamente, uma vez que suas propriedades têm sido pouco observadas quando administradas de forma aguda (devido ao lento esvaziamento gástrico e níveis de lipídios elevados), o que poderia comprometer o desempenho atlético durante a prática esportiva. (FRAGA et al., 2005; MATHUR et al., 2002).

Partindo destes princípios, este estudo tem como objetivo analisar a influência de diferentes protocolos de suplementação (solução isotônica e/ou chocolate) no metabolismo hidroeletrolítico de atletas profissionais de futebol de campo submetidos a uma condição real de treinamento esportivo.

\section{MATERIAL E MÉTODOS}

\section{AMOSTRA}

Participaram do estudo de 24 jogadores profissionais de futebol, da primeira divisão de futebol estadual, do sexo masculino (idade: $23 \pm 3$ anos; estatura: I $80 \pm 5 \mathrm{~cm}$; peso: $78 \pm 6 \mathrm{~kg}$; IMC: $24,1 \pm 1,5 \mathrm{~kg} / \mathrm{m}^{2}$ ), que treinavam regularmente 
há mais de um ano; 30 dias após o início da temporada; usando tênis à prova de impacto. Os jogadores foram divididos igualitariamente de acordo com a posição de jogo (goleiro, zagueiro, lateral, meio-campo e atacante) em quatro grupos experimentais, i.e.: (Gl) fizeram reposição hídrica com água ad libidum,; (G2) fizeram suplementação prévia ao treinamento com chocolate e reposição hídrica com água ad libidum; (G3) fizeram reposição hídrica com 600ml de bebida esportiva; e (G4) fizeram suplementação com chocolate e reposição hídrica com $600 \mathrm{ml}$ de bebida esportiva.

Ao grupo tratado com chocolate, foi fornecido uma barra de $100 \mathrm{~g}$ de chocolate ao leite 30 minutos antes do treinamento e/ou reidratação com bebida isotônica constituída de $42 \mathrm{mg} / \mathrm{dl}$ de cloretos, $12 \mathrm{mg} / \mathrm{dl}$ de potássio, $45 \mathrm{mg} / \mathrm{dl}$ de sódio e 6g/dl de glicose, aprovada para comercialização pela Agência Nacional de Vigilância Sanitária (ANVISA) e Food Drug and Administration (FDA). Nenhum dos atletas era fumante; não possuíam histórico de doenças crônico/degenerativas ou fazia uso de medicação no momento da análise. Todos aceitaram participar do estudo voluntariamente, e assinaram o termo consentimento informado conforme o Código de Nuremberg (1947), Declaração dos Direitos do Homem (1948) e a Declaração de Helsinque ( 1964). O Projeto foi submetido e aprovado pelo comitê de ética em pesquisa, segundo o regulamento 196/1996 do Conselho Nacional de Saúde, sob registro nº 748/2005.

\section{PROTOCOLO EXPERIMENTAL}

$\bigcirc$ treino ocorreu às 9 horas da manhã em um campo de futebol, com duração aproximada de 90 minutos; a uma altitude de $687 \mathrm{~m}$ do nível do mar. Os testes foram realizados a uma temperatura ambiente de $28^{\circ} \mathrm{C}$ e $60 \%$ de umidade relativa do ar. Os jogadores realizaram o treino com roupas leves.

treinamento executado pelos jogadores foi dividido em três partes:

- Aquecimento: 15 minutos de corrida leve em pista de saibro;

- Treinamento em quadra de areia: 6 séries de saltos sobre 5 cones retornando com sprint de 10 metros com I minuto de recuperação entre cada série, e a realização de 6 séries de 3 sprint de 10 metros retornando de costas em cada repetição, com I minuto de recuperação entre cada série;

- Recondicionamento: corrida leve de 20 minutos na grama. 
Amostras de sangue foram coletadas assepticamente da fossa antecubital dos atletas, em repouso e 15 minutos após o término do treinamento; $2 \mathrm{~mL}$ de sangue foram acondicionados em um frasco contendo $2 \mathrm{mg} / \mathrm{mL}$ de etilenodiaminotetracético (EDTA) para análise hematológica. O restante da amostra colhida $(8 \mathrm{~mL})$ foi acondicionada sem anticoagulante (EDTA) em um tubo de ensaio; centrifugada a I 500 rpm durante I 5 minutos; o soro foi extraído e acondicionado em tubos Eppendorff para realização das dosagens bioquímicas.

Da amostra de sangue anticoagulado com EDTA, procedeu-se à contagem eletrônica de células por análise de impedância $\left(\right.$ Coulter T890 ${ }^{\circledR}$ ). A contagem diferencial dos leucócitos foi realizada mediante análise microscópica de 100 células (Nikon Eclipse $600^{\circledR}$ ) em uma distensão sanguínea corada pelo método de Romanowsky $\left(\right.$ Merck $\left.^{\circledR}\right)$. A análise diferencial das linhagens celulares foi expressa em contagem relativa (células/\%) e contagem absoluta (células/ $\mu \mathrm{L}$ ).

Da amostra colhida sem anticoagulante, o soro foi extraído, e realizada a determinação de cálcio, fósforo, magnésio, glicose; colesterol total e frações; triglicerídeos, ácido úrico sérico e urinário, creatinina sérica e urinária, ureia sérica e urinária, proteína totais sérica urinária, lactato desidrogenase, Alanina aminotransferase e aspartato aminotransferase utilizando kits comerciais fabricados por Labtest Diagnóstica ${ }^{\circledR}$. A análise espectrofotométrica foi realizada em equipamento semi-automatizado Celm SB-190.

Sódio, potássio e cloretos foram determinados pelo método de eletrodo íon seletivo (Medica EasyLite ${ }^{\circledR}$ ).

Também foram coletados aproximadamente $50 \mathrm{~mL}$ de urina, jato médio, em frascos coletores universais, dos atletas em repouso e 15 minutos após o treinamento. As amostras foram acondicionadas em frascos padrão para análise urinária. Imediatamente as amostras foram processadas seguindo o procedimento recomendado pela Clinical and Laboratory Standards Institute (CLSI) e Associação Brasileira de Normas Técnicas (documento ABNT-CB 36), seguido de análise físico-química e microscópica.

A análise físico-química foi realizada por meio da observação visual do aspecto e coloração da urina; a densidade foi determinada com refratômetro $\left(\mathrm{LF}^{\circledR}\right)$. A análise química foi feita usando fita de polieletrólitos (Combur Test Dade-Behring ${ }^{\circledR}$ ), para detectar a presença de proteínas, glicose, nitrito, bilirrubina, corpos cetônicos, leucócitos, pH, sangue e urobilinogênio na amostra de urina não centrifugada. A análise microscópica foi feita analisando o sedimento urinário para quantificação de células epiteliais, cristais, leucócitos, hemácias, bactérias, filamento de muco e cilindros. 


\section{ANÁLISE DOS DADOS}

Para a análise dos efeitos agudos do exercício sobre a homeostase eletrolítica comparada com repouso (independentemente do protocolo de suplementação), os resultados foram agrupados em dois grupos (repouso e após o treinamento), a seguir analisados mediante comparação de médias pelo teste paramétrico t de Student para amostras pareadas e o teste de Wilcoxon-Mann-Whitney para análise de dados não-paramétricos com nível mínimo de significância de $p<0,05$.

Para análise do efeito dos diferentes protocolos de suplementação durante o treinamento, as diferenças de médias dos grupos experimentais (GI, G2, G3 e G4) foram analisados mediante análise de variância (ONE WAY ANOVA), seguido de análise "pos hoc" utilizando o teste de Tukey para os dados paramétricos, e o teste de Kruskall-Wallis para dados não-paramétricos, com nível mínimo de significância de $p \leq 0,05$.

\section{RESULTADOS}

A análise estatística dos resultados demonstrados na Tabela I mostra uma elevação estatisticamente significante $(p<0,05)$ na contagem de neutrófilos e na concentração de ácido úrico, glicose e triglicerídeos, combinadas a um decréscimo $(p<0,05)$ na contagem de linfócitos e na concentração de magnésio, sódio, potássio, fósforo e de VLDL-C, independentemente do protocolo de suplementação.

Tabela I. Análise estatística do efeito do treinamento esportivo comparado com o repouso por análise de dados paramétricos pelo teste t de Student para amostras pareadas, independentemente do protocolo de suplementação alimentar. Resultados expressos como média \pm erro padrão

\begin{tabular}{|c|c|c|c|}
\hline & Repouso & Após esforço & $P$ \\
\hline Contagem relativa de linfócitos (cels/\%) & $38,9 \pm 2,2$ & $33,0 \pm 1,6$ & $0,034 *$ \\
\hline Contagem relativa de Neutrófilos Segmentados (cels/\%) & $47,5 \pm 2,1$ & $56,3 \pm 2,0$ & $0,002 *$ \\
\hline Contagem Absoluta de Neutrófilos Segmentados (cels/ml) & $2772,5 \pm 205,6$ & $3969,3 \pm 232,6$ & $<0,00$ I* \\
\hline Contagem Absoluta de Neutrófilos Bastonetes (cels/ml) & $171,7 \pm 18,6$ & $258,7 \pm 34,6$ & $0,011 *$ \\
\hline Magnésio Sérico (mg/dl) & $2,2 \pm 0,0$ & $1,7 \pm 0,0$ & $<0,00$ I* \\
\hline Sódio Sérico (mEq/l) & $146,8 \pm 3,0$ & $136,5 \pm 1,4$ & $0,004 *$ \\
\hline Ácido úrico Sérico (mg/dl) & $4,3 \pm 0,2$ & $5,1 \pm 0,2$ & $<0,00$ I* \\
\hline Potássio Sérico (mEq/L) & $4,5 \pm 0,2$ & $3,4 \pm 0,1$ & $<0,00$ I* \\
\hline Fósforo Sérico (mEq/L) & $3,7 \pm 0,1$ & $2,9 \pm 0,2$ & $0,004 *$ \\
\hline Glicose sérica (mg/dl) & $82,2 \pm 2,5$ & $100,9 \pm 2,9$ & $<0,00$ I* \\
\hline Triglicerídeos (mg/dl) & $81,5 \pm 5,9$ & $106,9 \pm 10,0$ & $<0,\left.00\right|^{*}$ \\
\hline Colesterol VLDL (mg/dl) & $16,3 \pm 1,2$ & $3,3 \pm 0,3$ & $<0,00$ I* \\
\hline
\end{tabular}


A Tabela I aponta que independentemente da reposição hidroeletrolótica realizada pelos atletas, o protocolo de treinamento aplicado promoveu um aumento estatisticamente significante na contagem de neutrófilos, provavelmente por ação adrenérgica (Andersen et al., 2004), glicose (pela suplementação e pela glicogenólise hepática e muscular), ácido úrico e triglicerídeos, associado a um decréscimo estatisticamente significante da contagem de linfócitos, magnésio, sódio, potássio, fósforo e colesterol VLDL.

A análise estatística dos demais parâmetros do hemograma; Proteínas séricas e urinárias; Uréia Sérica e urinária; Creatinina Sérica e urinária; ácido úrico urinário; AST; ALP; Lactato Desidrogenase Total; Cálcio; Colesterol LDL; Cloro; Colesterol total; Colesterol HDL não mostrou diferença significante ( $p>0,05)$.

Tabela 2. Análise do efeito do treinamento agudo sobre parâmetros do sedimento urinário da urina dos atletas em repouso e 15 minutos após treinamento, desconsiderando os protocolos de reposição eletrolítica e de carboidratos. Resultados expressos como média \pm erro padrão. *p $<0,05$ em rela-

ção ao repouso pelo teste $T$ de Student para amostras pareadas para dados paramétricos

\begin{tabular}{cccc}
\hline PARÂMETRO & REPOUSO & APÓS EXERCÍCIO & P \\
\hline Contagem máxima de cilindros hialinos & $0,09 \pm 0,06$ & $2,4 \pm 0,6$ & $0,003^{*}$ \\
\hline
\end{tabular}

A análise estatística dos resultados obtidos para Contagem mínima e máxima de hemácias; Contagem mínima e máxima de leucócitos; Densidade; não mostraram diferença significante $(p>0,05)$.

TABELA 3. Análise do efeito do treinamento agudo sobre o exame físico-químico da urina dos atletas em repouso e 15 minutos após treinamento, desconsiderando os protocolos de reposição eletrolítica e de carboidratos. Resultados expressos como média \pm erro padrão. * $p<0,05$ em relação ao repouso pelo teste de Wilcoxon-Mann-Whitney para dados não-paramétricos

\begin{tabular}{cccc}
\hline PARÂMETRO & REPOUSO & APÓS EXERCÍCIO & $P$ \\
\hline Cor & $1,2 \pm 0,09$ & $1,7 \pm 0,1$ & $0,007^{*}$ \\
Filamento de muco & $0,9 \pm 0,2$ & $1,7 \pm 0,1$ & $0,003^{*}$ \\
Proteínas & $0,09 \pm 0,09$ & $0,5 \pm 0,1$ & $0,046^{*}$ \\
\hline
\end{tabular}

A análise estatística do Aspecto; Sangue (Hemácias e hemoglobina); Bilirrubina; Urobilinogênio; Cetonas; Glicose; Nitrito; Leucócitos; pH; Células epiteliais e Bactérias não mostraram diferença significante $(p>0,05)$.

Análise do efeito da suplementação eletrolítica e carboidratos sobre o exame físico-químico da urina dos atletas em repouso e 15 minutos após treinamento pela análise de variância e análise post hoc de Tukey para dados paramétricos mostra 
que a contagem mínima e máxima de hemácias; contagem mínima e máxima de leucócitos; densidade; contagem mínima e máxima de cilindros hialinos na urina não mostrou diferença estatística significante ( $p>0,05)$.

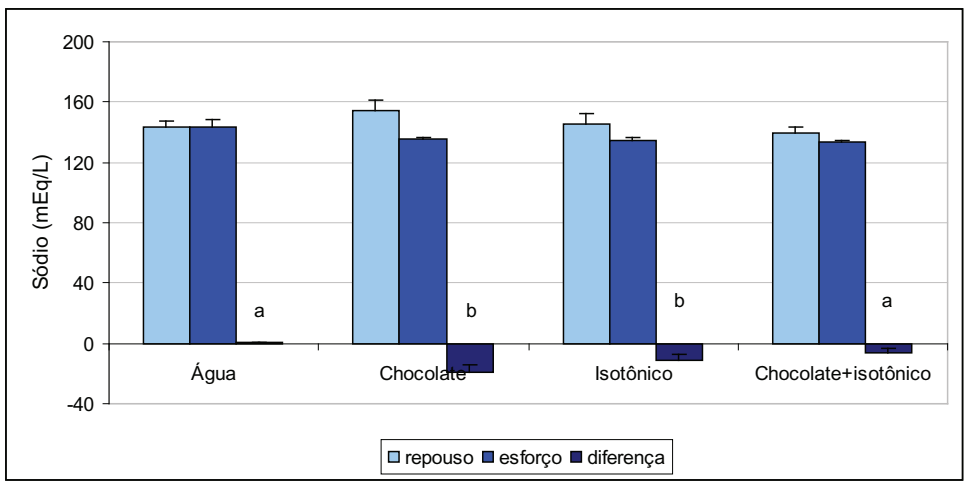

Figura I. Análise estatística do efeito do treinamento esportivo sobre a concentração de sódio plasmático de atletas de futebol tratados com diferentes protocolos de suplementação eletrolítica. Análise de dados paramétricos por análise de variância (One Way ANOVA) seguido do teste de Tukey considerando o protocolo de suplementação. Resultados expressos como média \pm erro padrão. Letras iguais em uma mesma coluna significam que não houve diferença estatística. Letras diferentes significam que ocorreu diferença significativa $(p<0,05)$.

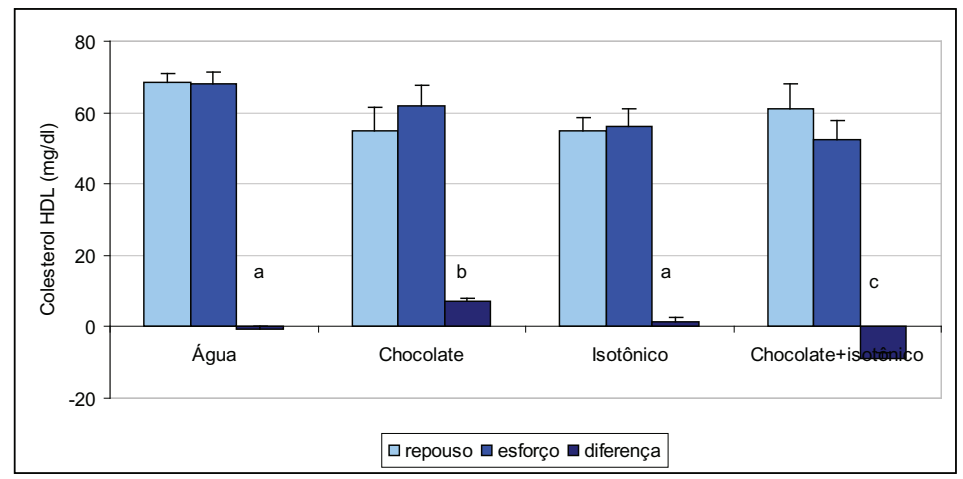

Figura 2. Análise estatística do efeito do treinamento esportivo sobre a concentração de colesterol $\mathrm{HDL}$ de atletas de futebol tratados com diferentes protocolos de suplementação eletrolítica. Análise de dados paramétricos por análise de variância (One Way ANOVA) seguido do teste de Tukey considerando o protocolo de suplementação. Resultados expressos como média \pm erro padrão. Letras iguais em uma mesma coluna significam que não houve diferença estatística. Letras diferentes significam que ocorreu diferença significativa $(p<0,05)$. 
Análise do efeito da suplementação eletrolítica e carboidratos sobre os exames bioquímicos dos atletas em repouso e 15 minutos após treinamento pela análise de variância, seguido de análise post hoc de Tukey para dados paramétricos, mostra que o hemograma, Proteínas séricas e urinárias; Ureia Sérica e urinária; ácido úrico sérico e urinário; Creatinina Sérica e Urinária; AST; ALP; Lactato Desidrogenase Total; Cálcio; Magnésio; Cloro; Potássio; Fósforo; Glicose; Colesterol total; Triglicerídeos; Colesterol VLDL; Colesterol LDL não apresentaram diferença significante ( $p>0,05)$.

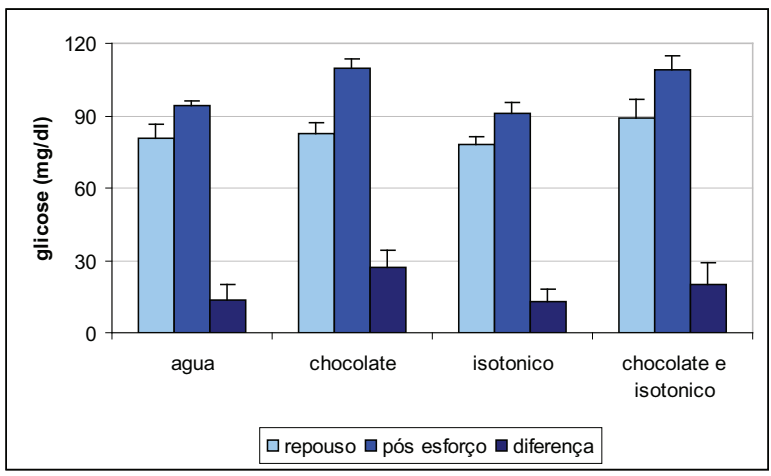

Figura 3. Análise estatística do efeito do treinamento esportivo sobre a concentração de glicose de atletas de futebol tratados com diferentes protocolos de suplementação eletrolítica. Análise de dados paramétricos por análise de variância (One Way ANOVA) seguido do teste de Tukey considerando o protocolo de suplementação. Resultados expressos como média \pm erro padrão. Letras iguais em uma mesma coluna significam que não houve diferença estatística. Letras diferentes significam que ocorreu diferença significativa $(p<0,05)$

Análise do efeito da suplementação eletrolítica e carboidratos sobre o exame físico-químico da urina dos atletas em repouso e 15 minutos após treinamento utilizando o teste de Kruskal Wallis para dados não-paramétricos mostra que a Cor; Aspecto; Sangue (Hemácias e hemoglobina); Bilirrubina; Urobilinogênio; Cetonas; Glicose; Proteínas; Nitrito; Leucócitos; pH; Células epiteliais; Bactérias e Filamentos de muco não apresentaram diferença significante $(p>0,05)$.

\section{DISCUSSÃO}

A análise dos resultados mostrou que os atletas apresentaram um decréscimo estatisticamente significante nos níveis séricos de potássio $(p<0,00$ I $)$ após o treinamento, quando comparado com o repouso. 
A análise dos resultados para os efeitos da suplementação sobre o metabolismo do potássio mostrou que o decréscimo de potássio não foi corrigido por nenhum protocolo de suplementação. Durante a excitação de músculos ativos pode ocorrer uma maior passagem de potássio da corrente circulatória para o meio intersticial, desencadeando a queda da concentração plasmática de potássio. Além disso, a liberação de aldosterona em resposta a queda da concentração de sódio, promove uma maior recaptação tubular deste íon combinada a uma maior perda de potássio e íons $\mathrm{H}^{+}$pela urina. (NAVES et al., 2003; JUEL et al., 2000).

O protocolo de treinamento realizado mostra que a análise da concentração de sódio (tabela I), desconsiderando o protocolo de suplementação, apresentou um decréscimo estatisticamente significante $(p<0,05)$, que pode ser explicado pelo fato de o sódio ser o principal eletrólito eliminado pelo suor durante uma atividade física intensa. (CHEUVRONT et al., 20 I0; BRITO et al., 2005; PERRELA et al., 2005; ARMSTRONG et al., 2007). A perda excessiva do sódio pode gerar um estado de hiponatremia em atletas, entretanto, este quadro não é comum, sendo mais frequentemente observado em exercícios com mais de $4 \mathrm{~h}$ de duração ou pela ingestão de grandes quantidades de água sem ingestão de sódio. (BRITO, et al., 2005; STEPHENS et al., 2007). No entanto, quando considerado o protocolo de suplementação (FIGURA I), observa-se que o grupo suplementado somente com água e no grupo com a combinação chocolate mais isotônico, a queda dos níveis plasmáticos de sódio foram surpreendentemente menores que o grupo suplementado com chocolate ou isotônico isoladamente. Uma hipótese a ser considerada é o fato de que o processo de absorção de glicose requerer sódio no lúmen intestinal pode ter acarretado numa menor concentração de sódio plasmático. (BURKE, 200 I).

A dosagem da concentração sérica de glicose mostrou um aumento estatisticamente significante $(p<0,00$ I) para os efeitos pós-esforço, quando comparada à concentração sérica de repouso. Durante o exercício os níveis de catecolaminas (adrenalina e noradrenalina) se elevam promovendo um aumento da glicogenólise, tanto no fígado quanto no músculo, e um aumento na liberação de glicose para a corrente sanguínea. (CANALI; KRUEL, 200 I). A análise dos efeitos da suplementação com carboidratos e bebidas esportivas sobre a glicemia após treinamento, possibilitou observar que os resultados não apresentaram diferença estatisticamente significante $(p>0,05)$ entre os grupos. Recomenda-se o uso de outras fontes de carboidratos em detrimento do chocolate, em virtude de seu lento esvaziamento gástrico e elevado teor de gorduras.

A análise do efeito do exercício sobre o metabolismo do magnésio mostrou um decréscimo estatisticamente significante $(p<0,00$ I ) após o treinamento, quando comparado com o repouso. O magnésio é um importante cofator de enzimas envolvidas 
na rota glicolítica. $\bigcirc$ aumento do consumo de substratos energéticos utilizados para contração muscular pode induzir a um maior consumo deste íon para atividade enzimática na rota glicolítica (COWAN, 2002). Além disso, o exercício estimula a ação de osteoblastos na epífise óssea, que induz a uma maior captação de magnésio para fortalecimento ósseo mediante a formação de hidroxiapatita juntamente com cálcio e fósforo (WEBSTER et al., 2002), que corrobora os resultados encontrados no presente estudo. A análise do efeito da suplementação com chocolate e bebida isotônica no metabolismo do magnésio, mostrou que os atletas não apresentaram diferença estatisticamente significante nos níveis séricos de magnésio $(p>0,05)$ após o treinamento.

A dosagem da concentração sérica de fósforo mostrou um decréscimo estatisticamente significante $(p<0,05)$ após o treinamento quando comparado com o repouso. $\bigcirc$ fósforo é componente essencial na formação óssea, do mediador intracelular monofosfato de adenosina (AMP) cíclico e dos compostos intramusculares de alta energia. Durante a atividade física tem-se uma diminuição de fosfato plasmático, pela regeneração de ATP e intermediários de alta energia. Cabe ressaltar a participação do fósforo no fortalecimento ósseo, na medida em que a força mecânica proporcionada pelo exercício estimula a atividade osteoblástica. $\bigcirc$ estresse mecânico provocado pelo exercício diminui as concentrações séricas de fósforo para maior formação ou regeneração óssea dentro da matriz óssea, principalmente em atividades que tenham maior tração óssea. (WEBSTER et al., 2002). No entanto, a análise do efeito da suplementação sobre o metabolismo do fósforo permitiu verificar que todos os tipos de suplementação foram ineficazes para a correção da hipofosfatemia apresentada.

A análise dos resultados para os efeitos do treinamento no metabolismo eletrolítico mostrou que os atletas não apresentaram alterações significantes nos níveis séricos de cloro ( $p>0,05)$. O cloro, juntamente com o sódio e potássio, é responsável pela manutenção do equilíbrio e distribuição de água, do equilíbrio osmótico normal, equilíbrio ácido-base e do ritmo cardíaco. (WILMORE et al., 200 I). Quando o suor é eliminado, diversos fatores interferem na sua composição, porém entre os eletrólitos, os que sofrem maiores modificações são o sódio e o cloreto, cuja concentração é mais elevada no plasma. (ARMSTRONG et al., 2007).

A análise efeito do exercício sobre os resultados do exame físico-químico da urina mostra que houve um escurecimento estatisticamente significante na coloração da urina $(p<0,0 \mathrm{I})$, refletindo a quantidade de urocromo produzido e que depende do estado metabólico do corpo, que está diretamente relacionada com o grau de hidratação dos indivíduos, indicando um aumento da concentração de solutos. (TOPHAM, 2004; BELLINGHIERI et al., 2008; LÜTHJE et al., 2004) . No 
entanto, análise do efeito da suplementação com eletrólitos e carboidratos aponta que este aumento ocorreu em todas as amostras, independente do protocolo de suplementação, e que mostrou ser inerente ao processo de treinamento realizado.

A análise dos resultados mostra que o exercício provocou um aumento significante na proteinúria $(p<0,05)$ cilindrúria e filamento de muco (ambos, com $p<0,0$ I ) após a realização do esforço físico. Estes resultados concordam com Tophan (2004), que apontam que a causa primária destas alterações está relacionada com a atividade física intensa, desidratação, estresse emocional ou outros mecanismos fisiopatológicos como: glomerulares, tubulares e hiperfiltração. (TOPHAM, 2004; BELLINGHIERI et al., 2008; LÜTHJE et al., 2004). Durante o exercício físico pode ocorrer uma proteinúria funcional, decorrente de alterações nas pressões hidrostáticas e coloidosmóticas no glomérulo, que promove um acréscimo na força de filtração, ocasionando um aumento na permeabilidade da membrana glomerular, deixando passar para o filtrado uma variável quantidade de proteínas séricas. Por outro lado, a análise da influência da suplementação com eletrólitos e carboidratos mostra que a proteinúria e cilindrúria apresentada acometeu todos os grupos, independentemente do protocolo de suplementação, com igual intensidade. Indicando que este quadro pode não estar relacionado com o grau de hidratação dos indivíduos, mas sim, com a relação da pressão hidrostática e coloidosmótica inerente ao protocolo de treinamento realizado, o que poderia ser reavaliado em estudos futuros.

A análise dos resultados sobre os efeitos agudos do exercício no sangue periférico mostrou uma neutrofilia (contagem absoluta de neutrófilos $p<0,00$ I) com desvio à esquerda (contagem absoluta de bastonetes $p<0,0$ I), combinada a uma linfocitopenia espúria $(p<0,05)$, pois houve elevação desproporcional do número de neutrófilos quando comparado com o número de linfócitos. A resposta dos neutrófilos a uma sessão única de exercício está na dependência da intensidade deste. A prática de exercício durante alguns minutos ou durante horas provoca leucocitose, sendo resultante do aumento no débito cardíaco, mobilização do pool marginal de leucócitos e o efeito de catecolaminas, cortisol, hormônio do crescimento $(\mathrm{GH})$, peptídeos opioides (endorfinas) e também elementos como interferons, interleucinas, fatores de necrose tumoral e outras citocinas. (BONSIGNORE et al., 2002; COSTA ROSA; VAISBERG, 2002)

A comparação das diferenças de médias dos grupos experimentais mostra que a suplementação com eletrólitos e carboidratos não interfere significativamente na neutrofilia induzida pelo esforço, demonstrando que está mais relacionada com descargas hormonais que distúrbios eletrolíticos. 
As alterações descritas referem-se à resposta ao exercício agudo, podendo ser entendidas como uma resposta ao estresse. Fica bem claro que, embora sejam transitórias, tais alterações podem assumir importância em decorrência da queda de algumas funções da resposta imune frente a exercícios de alta intensidade. No entanto, mesmo frente a estímulo de alta intensidade, a resposta de neutrófilos e macrófagos se mantém ou até mesmo se mostra aumentada.

O aumento na utilização de substratos como fonte energética durante a realização de exercício físico pode diminuir os estoques de carboidratos dos atletas e aumentar o catabolismo proteico para suprir a necessidade energética. (LAZZAROTTO et al., 20 I 0; BURKE, 200 I). A elevação da glicemia dos atletas dos diferentes grupos após a realização do treino, mesmo apresentando diferença entre eles (G2 e G4 apresentaram aumento significativo na glicemia, diferentemente dos grupos GI e G3), pode ter causado um efeito protetor no catabolismo proteico (FIGURA 3).

A análise da função renal dos atletas não mostrou diferença significativa após o treinamento, pela análise da concentração de creatinina e ureia sérica e urinária e da proteinúria. Além disso, a determinação da concentração de creatinina sérica e urinária pode ser uma medida indireta da atividade do sistema de fosfagênios.

A hidratação com água ou com bebida isotônica foi de aproximadamente $600 \mathrm{ml}$, em média, para 90 min de treino. É possível que o volume de eletrólitos não tenha sido suficiente, sugerindo que acima de $30^{\circ} \mathrm{C}$ é recomendável ingerir em torno de $600 \mathrm{ml} / \mathrm{h}$ de líquidos, independentemente da vontade do atleta, ou verificar a aceitabilidade de uma bebida com uma maior concentração de eletrólitos, uma vez que alteraria as propriedades organolépticas da bebida e consequentemente a sua aceitabilidade.

Recomenda-se que os atletas devam ser estimulados a consumir fontes naturais de eletrólitos como frutas, vegetais e sucos antes dos treinos em detrimento das fontes sintéticas, por questões de biodisponibilidade destes elementos.

\section{CONCLUSÃO}

treinamento realizado por atletas profissionais de futebol, nas condições propostas, provocou uma redução plasmática de sódio, potássio, magnésio e fósforo que não foi corrigida pelos protocolos de suplementação propostos.

A análise dos resultados sugere que a suplementação com carboidratos e bebidas esportivas sobre o metabolismo eletrolítico de atletas profissionais de futebol foi limitada, mas é importante salientar que vários procedimentos adaptativos que acompanham um condicionamento físico ideal ajudam a prevenir problemas relacionados à desidratação. E ainda fatores como o estado nutricional, variações 
individuais, entre outros, devem ser avaliados antes de se poder afirmar se a suplementação com carboidratos e bebidas esportivas possui ou não efeito positivo sobre o rendimento de uma atividade física.

Os resultados aqui elencados apontam que a prática esportiva pode potencialmente induzir a distúrbios hidroeletrolíticos e processos catabólicos perniciosos, mas que podem ser diagnosticados laboratorialmente e prevenidos mediante uma reposição alimentar adequada proporcional à carga de trabalho do atleta.

\section{Analysis of carbohydrate supplementation and isotonic solution} hematological and biochemical parameters on professional soccer players in real training

ABSTRACT: The aim of this study was evaluate the effect of supplementation with carbohydrate sports drinks and laboratory parameters in athletes on the football field, in a real training. 10 $\mathrm{ml}$ of venous blood and $50 \mathrm{ml}$ of urine were collected at rest and 15 minutes after training. The results show that intense exercise caused a variable degree of urinary stasis and electrolyte changes caused by a marked decrease in serum sodium, potassium, magnesium, phosphorus and glucose $(p<0.05)$, which was not modified by any type of supplementation protocol under the conditions proposed in this study. The proposed electrolyte supplementation was shown to be limited to prevent electrolyte variations and that the recovery must be evaluated in light of an environmental and training context.

KEYWORDS: Electrolytes; water-electrolyte balance; dehydration; dietary supplements.

\section{El análisis de los suplementos de hidratos de carbono en solución isotónica y parámetros hematológicos y bioquímicos de jugadores profesionales de fútbol en entrenamiento real}

RESUMEN: Se evaluó el efecto de la suplementación con una bebida deportiva con carbohidratos y los parámetros de laboratorio en los atletas en el campo de fútbol, en un entrenamiento real. Se recogieron $10 \mathrm{ml}$ de sangre venosa y $50 \mathrm{ml}$ de orina en reposo y 15 minutos después del entrenamiento. Los resultados muestran que el ejercicio intenso causado un grado variable de la estasis urinaria y los cambios de electrolitos causados por una marcada disminución de niveles séricos de sodio, potasio, magnesio, fósforo y glucosa ( $p<0,05)$, que no fue modificado por cualquier tipo de protocolo de suplementación en las condiciones propuestas en este estudio. La suplementación de electrolitos propuesta demostró ser limitada para evitar las variaciones de los electrolitos y que la recuperación debe ser evaluada a la luz de un entorno ambiental y de entrenamiento.

PALABRAS CLAVE: Electrolitos; equilibrio electrolítico; el estrés hídrico; suplemento dietético. 


\section{REFERÊNCIAS}

ANDERSEN, S. K. et al. The roles of insulin and hyperglycemia in sepsis pathogenesis Journal of Leukocyte Biology, Bethesda, v. 75, n. I, p. 413-421, 2004.

ARMSTRONG, L. E. et al. Caffeine, Fluid-electrolyte balance, temperature regulation, and exercise-heat tolerance. Exercise \& Sport Sciences Reviews, Indianapolis, v. 35, n. 3, p. I35I 40, jul. 2007.

BEHM, D. G et al. Canadian society for exercise physiology position paper: resistance training in children and adolescents. Applied Physiology, Nutrition and Metabolism, Ottawa, v 33, n 3 , p. 547-56I, jun. 2008 .

BELLINGHIERI, G. et al. Renal alterations during exercise. Journal of Renal Nutrition, Philadelphia, v. I, n. 18, p. 158-64, jan. 2008.

BONSIGNORE, M. R. et al. Circulating hematopoietic progenitor cells in runners. Journal of Applied Physiology, Bethesda, v. 12, n. 93, p. 169|-1697, jul. 2002.

BORTOLOTTI, H. et al. Carbohydrate mouth rinse: an ergogenic aid able of optimizing the performance. Brazilian Journal of Kinanthropometry and Human Performance, Florianópolis, v. 13, n. 2, p. |58-161, mar./abr. 201।.

BRITO, C. J. et al. Caracterização das práticas sobre hidratação em atletas da modalidade de judô no estado de Minas Gerais. Revista Brasileira de Ciências e Movimento, Brasilia, v. I 3, n. 2, p. 59-74, abr./jun. 2005.

BURKE, L. M. Nutritional needs for exercise in the heat. Comparative Biochemistry and Physiology Part A Molecular Integrated Physiology, London, v. I28, n 4, p. 735-48, apr. 200 I.

CANALI, E. S.; KRUEL, L. F. M. Respostas hormonais ao exercício. Revista Paulista de Educação Física, São Paulo, v. 2, n. 15, p. |4|-153, jul./dez. 200 I.

CARVALHO, T. et al. Hidratação e nutrição no esporte. Revista Brasileira de Medicina do Esporte, São Paulo, v. 16, n. 2, p. |44-|48, mar./apr. 2010.

CHEUVRONT, S. N. et al. Mechanisms of aerobic performance impairment with heat stress and dehydration. Journal of Applied Physiology, Bethesda, v. 109, n. 6, p. 1989-1995, dec. 2010.

COSTA ROSA, L. F. P. B.; VAISBERG, M. W. Influências do exercício na resposta imune. Revista Brasileira de Medicina do Esporte, São Paulo, v. 8, n. 4, p. I67-172, jul./ago. 2002.

COWAN J. A. Structural and catalytic chemistry of magnesium-dependent enzymes. BioMetals, Amsterdam, v. I5, n. 3, p. 225-235, 2002.

FALLER, A. L. K.; FIALHO, E. Disponibilidade de polifenóis em frutas e hortaliças consumidas no Brasil. Revista de Saúde Pública, São Paulo, v. 43, n. 2, p. 2 II -218, 2009. 
FRAGA, C. G. et al. Regular consumption of a flavanol-rich chocolate can improve oxidant stress in young soccer players. Clinical Development Immunology, New York, v. I2, n. I, p. | |- |7, mar. 2005.

IRIGOYEN, M. C. et al. Controle cardiovascular: regulação reflexa e papel do sistema nervoso simpático. Revista Brasileira de Hipertensão, São Paulo, v. 8, n. I, p. 55-62, 2001.

JUEL, C. et al. Interstitial $\mathrm{K}^{+}$in human skeletal muscle during and after dynamic graded exercise determined by microdialysis. Journal of Applied Physiology, Bethesda, v. 278, n. 2, p. 400-406, feb. 2000.

KANNO, P. et al. Ideal diet versus athletic performance: a study about nutritional stereotypes applied by triathletes. Brazilian Journal of Kinanthropometry and Human Performance, Florianópolis, v. II, n.4, p. 444-448, sept. 2009.

LAZZAROTTO, A. R. et al. Treinamento concorrente: a revisão sistemática. Revista Brasileira de Medicina do Esporte, São Paulo, v. I6, n. 2, p. I49-I54, mar./abr. 2010.

LÜTHJE, P. et al. Recurrent macroscopic haematuria due to bladder blood vessels after exercise induced haematuria. British Journal of Sports Medicine, Loughborough, v. 38, n. 3/4, p. 38-44, jun. 2004.

MACHADO-MOREIRA, C. A. et al. Hidratação durante o exercício: a sede é suficiente? Revista Brasileira de Medicina do Esporte, São Paulo, v. I2, n. 6, p. 405-409, nov./dec. 2006.

MASTALOUDIS, A. et al. Antioxidant supplementation prevents exercise-induced lipid peroxidation, but not inflammation, in ultramarathon runners. Free Radical \& Medicine, Atlanta, v. 36, n. 10, p. 1329-1341, may 2004

MATHUR, S. et al. Cocoa products decrease low density lipoprotein oxidative susceptibility but do not affect biomarkers of inflammation in humans. Journal of Nutrition, Bethesda, Bethesda, v. 132, n 12, p. 3663-3667, dec. 2002.

MAUGHAN, R. et al. Rehydration and recovery after exercise. Science \& Sports, London, v. 19, n. 5, p. 234-238, oct. 2004.

MONTEIRO, C. R. et al. Hydration in soccer: a review. Revista Brasileira de Medicina do Esporte, São Paulo, v. 9, n. 4, p. 243-246, aug. 2003.

NAVES, L. A. et al. Distúrbios na secreção e ação do hormônio antidiurético. Arquivos Brasileiros de Endocrinologia e Metabologia, São Paulo, v. 47, n. 4, p. 467-48I, aug. 2003.

PANZA, V. P. et al. Consumo alimentar de atletas: reflexões sobre recomendações nutricionais, hábitos alimentares e métodos para avaliação do gasto e consumo energéticos. Revista de Nutrição, Campinas, v. 20, n. 6, p. 681-692, dez. 2007.

PERRELLA, M. M. et al. Avaliação da perda hídrica durante treino intenso de rugby. Revista Brasileira de Medicina do Esporte, São Paulo, v. I I, n. 4, p. 229-232, maio/jun. 2005.

PONCE, P. et al. Alterações urinárias induzidas pelo esforço físico. Acta Médica Portuguesa. Porto, v. 3, n. I, p. 209-21 I, maio/jun. 1988. 
REIN, D. et al. Epicatechin in human plasma: in vivo determination and effect of chocolate consumption on plasma oxidation status. Journal of Nutrition, Bethesda, v. 130, n. 8, p. 2109 2।|4, suppl., aug. 2000.

SHIN, Y. H. et al. Exercise self-efficacy, exercise benefits and barriers, and commitment to a plan for exercise among Korean women with osteoporosis and osteoarthritis. International Journal of Nursing Studies, New York, v. 43, n. I, p. 3-10, dec. 2006.

STEPHENS, B. R. et al. Effect of timing of energy and carbohydrate replacement on postexercise insulin action. Applied Physiology, Nutrition and Metabolism, Ottawa, v. 32, n. 6, p. | |39- | |47, dec. 2007.

TARNOPOLSKY, M. A. et al. Creatine-dextrose and protein-dextrose induce similar strength gains during trainin. Medicine \& Science in Sports \& Exercise, Indianapolis, v. 33, n. 12, p. 2044-2052, dec. 2001 .

THOMAS, K. et al. Improved endurance capacity following chocolate milk consumption compared with 2 commercially available sport drinks. Applied Physiology, Nutrition, and Metabolism, Ottawa, v. 34, n. I, p. 78-82, feb. 2009.

TOPHAM, P.S. et al. The value of urine screening in a young adult population. Family Practice, Oxford, v. 21, n. I, p. 18-21, feb. 2004.

WAN, Y. et al. Effects of cocoa powder and dark chocolate on LDL oxidative susceptibility and prostaglandin concentrations in humans. American Journal Clinical Nutrition, Bethesda, v. 74, n. 5, p. 596-602, nov. 2001.

WEBSTER, T. et al. Hydroxylapatite with substituted magnesium, zinc, cadmium, and yttrium. II. Mechanisms of osteoblast adhesion. Journal of Biomedical Materials Research New Jersey, v. 59 , n. 2, p. $312-317$, feb. 2002

WESTERBLAD, $\mathrm{H}$. et al. Skeletal muscle: Energy metabolism, fiber types, fatigue and adaptability. Experimental Cell Research, New York, v. 316, n. 18, p. 3093-3099, nov. 2010.

WILMORE, J. H. et al. Fisiologia do esporte e do exercício. 2. ed. São Paulo: Manole, 200 I.

Recebido: 04 jun. 201 I

Aprovado: 21 jan. 2012

Endereço para correspondência:

Prof. Dr. Luciano de O. Siqueira Universidade de Passo Fundo Instituto de Ciências Biológicas

Curso de Farmácia Br $285 \mathrm{Km} \mathrm{|7|}$ Cx. Postal 6 I I Bairro São José Passo Fundo-RS CEP 99052-900 